\title{
Chapter 10 \\ Bridging Behavior and Male-Infant \\ Interactions in Macaca thibetana \\ and $M$. assamensis: Insight into \\ the Evolution of Social Behavior \\ in the sinica Species-Group of Macaques
}

Hideshi Ogawa

\subsection{Introduction}

Species in the genus Macaca have many common features: forming multi-male multi-female social groups with female philopatry, male dispersal, and a linear dominance hierarchy (Thierry et al. 2004). However, there are variations in their "dominance style" and the degree of kin-biased social relationships between females (Berman and Thierry 2010; de Waal and Luttrell 1989). Recently, the variations in social relationships between females have been systematically studied (Balasubramaniam et al. 2012). In addition to social relationships between females, there are many inter-species differences in social relationships between males. Compared to females, however, there have been fewer comparative studies on social interactions between males. For example, frequent triadic male-infant interactions were reported in some macaque species, but not reported in most of other macaque species (Deag and Crook 1971; Kalbitz et al. 2017; Ogawa 1995, 2006). Therefore, in this paper, I focus on social interactions between adult males and infant handling by adult males in macaques.

Macaques are divided into several species-groups. Though there are several categorizations, one is the sinica species-group comprised of toque macaques (Macaca sinica) in Sri Lanka, Bonnet macaques (M. radiata) in India, Assamese macaques ( $M$. assamensis) from India to Southeast Asia, and Tibetan macaques (M. thibetana) in China. Delson (1980) included stump-tailed macaques (M. arctoides), which are distributed in India eastward to Southeast Asia, in the sinica species-group. Arunachal macaques (M. munzala) in the Arunachal area of India and white-cheeked macaques (M. leucogenys) in Tibet are recently listed as new species in the sinica species-group (Li et al. 2015; Sinha et al. 2005).

\section{H. Ogawa (凶)}

School of International Liberal Studies, Chukyo University, Toyota, Aichi, Japan e-mail: hogawa@lets.chukyo-u.ac.jp 
Assamese macaques have been traditionally divided into two subspecies, based on morphological traits (Fooden 1982). Eastern Assamese macaques (M. assamensis assamensis), which inhabit areas east of the Brahmaputra River, have shorter tails than western Assamese macaques (M. assamensis pelops), which inhabit areas west of the Brahmaputra River. Though Assamese macaques are widely distributed in Asia, direct observations of wild Assamese macaques are difficult, because they are patchy distributed in mountainous areas (Chalise et al. 2013; Wada 2005). There are only a few direct observations of wild Assamese macaques (Kalbitz et al. 2017). However, free-ranging Assamese macaques in several social groups are provisioned and habituated to humans at several locations. I observed free-ranging provisioned Assamese macaques in Thailand, India, and Nepal and compared these populations' social behaviors to those of Tibetan macaques in China.

As may occur with regard to genetic and morphological traits, inter-species and inter-subspecies differences in social behaviors could be affected by evolutionary divergence among populations. My aim in this study is to reconstruct the evolutionary processes of macaques' social behaviors by comparing the male-male and maleinfant interactions of Tibetan, eastern Assamese, and western Assamese macaques at various sites.

\subsection{Methods}

\subsubsection{Study Sites and Study Periods}

Tibetan macaques are distributed in China, and Assamese macaques are distributed in Nepal, India, Bhutan, Bangladesh, China, Myanmar, Laos, Thailand, and Vietnam (Groves 2001; Fooden 1982; Wada 2005). Among these countries, I conducted field researches at several sites in Nepal, India, China, and Thailand (Fig. 10.1).

\subsubsection{Western Assamese Macaque (M. a. pelops)}

Site 1 Ramdi Village $\left(27^{\circ} 54^{\prime} \mathrm{N}, 83^{\circ} 38^{\prime} \mathrm{E}, 437 \mathrm{~m}\right)$. I stayed at Ramdi Village, Pyuthan District, Nepal, from 20 to 23 March 2016 with Pavan Paudel. There were two provisioned groups of Assamese macaques around the village.

Site 2 Nagarjun $\left(27^{\circ} 44^{\prime} \mathrm{N}, 85^{\circ} 17^{\prime} \mathrm{E}, 1350-2093 \mathrm{~m}\right)$. Shivapuri-Nagarjun National Park, Kathmandu District, Nepal, has two separate areas, the Shivapuri area and the Nagarjun area. I stayed at Nagarjun for a total of 113 days between 2011 and 2017. Wild Assamese macaques in several social groups inhabit Nagarjun, as well as wild rhesus macaques (M. mulatta) (Chalise et al. 2013; Wada 2005). There is a royal palace and an active army camp in the national park, and soldiers live in the army camp. The social group of Assamese macaque was unintentionally provisioned by food waste of the army camp that was available for monkeys. Though I did not 


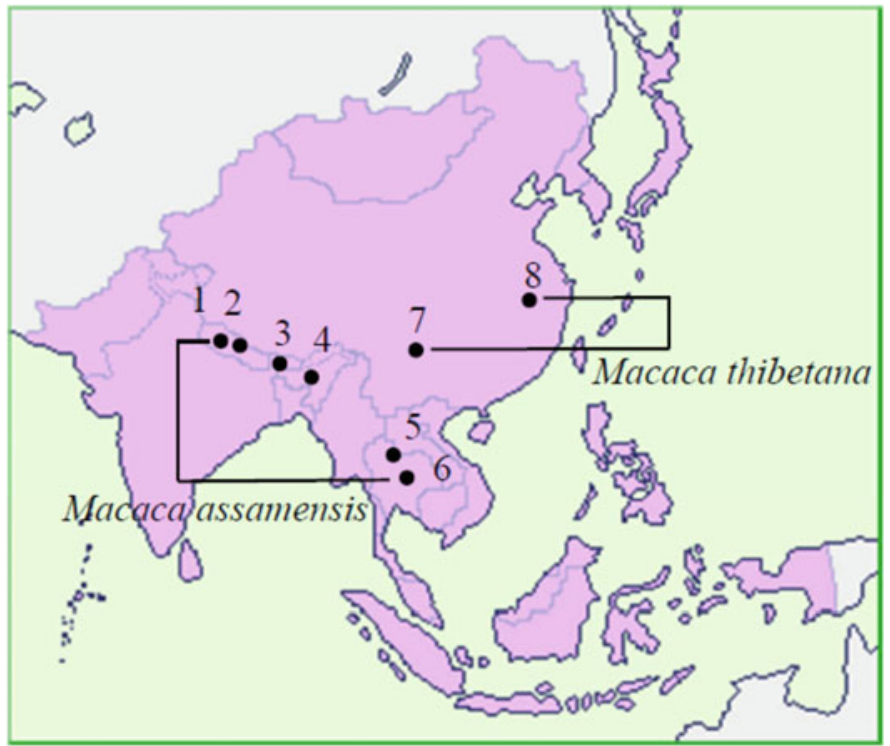

Fig. 10.1 Location of the study sites. 1, Ramdi Village $\left(27^{\circ} 54^{\prime} \mathrm{N}, 83^{\circ} 38^{\prime} \mathrm{E}\right) ; 2$, Nagarjun $\left(27^{\circ} 44^{\prime} \mathrm{N}\right.$, $\left.85^{\circ} 17^{\prime} \mathrm{E}\right) ; 3$, Siliguri $\left(26^{\circ} 54^{\prime} \mathrm{N}, 88^{\circ} 28^{\prime} \mathrm{E}\right)$; 4, Tukeswari Temple $\left(26^{\circ} 03^{\prime} \mathrm{N}, 90^{\circ} 38^{\prime} \mathrm{E}\right)$; 5 , Wat Tham Pla $\left(20^{\circ} 19^{\prime} \mathrm{N}, 99^{\circ} 51^{\prime}\right) ; 6$, Wat Tham Pha Tha Pol $\left(16^{\circ} 31^{\prime} \mathrm{N}, 100^{\circ} 40^{\prime} \mathrm{E}\right) ; 7$, Mt. Emei $\left(29^{\circ} 33^{\prime} \mathrm{N}\right.$, $\left.103^{\circ} 20^{\prime} \mathrm{E}\right) ; 8$, Huangshan $\left(30^{\circ} 29^{\prime} \mathrm{N}, 118^{\circ} 11^{\prime} \mathrm{E}\right)$

recommend it, when soldiers finished lunch and dinner, they usually disposed of their leftovers at a dumping site in the army camp. Monkeys consumed the garbage and became habituated to humans (Koirala et al. 2017). I identified all adult males and females in the AA group, based on their physical characteristics, and observed those monkeys with Sabina Koirala. The AA group was composed of 56 monkeys including 7 adult males, 13 adult females, 4 male infants ( $<1$ year old), and 1 female infant in January 2015.

Site 3 Siliguri $\left(26^{\circ} 54^{\prime} \mathrm{N}, 88^{\circ} 28^{\prime} \mathrm{E}, 199 \mathrm{~m}\right)$. I visited Coronation Bridge at Siliguri, West Bengal State, India, on 2 and 5 March 2009. Assamese macaques were provisioned and stayed along the road near Coronation Bridge.

\subsubsection{Assamese macaque (M. a. assamensis or M. a. pelops)}

Site 4 Tukreswari Temple $\left(26^{\circ} 03^{\prime} \mathrm{N}, 90^{\circ} 38^{\prime} \mathrm{E}, 47 \mathrm{~m}\right)$. I stayed near Tukreswari (Tukeswari) Temple, Assam State, India, from 22 to 25 February 2009 with Mayur Bawri. Assamese macaques in two social groups were provisioned and habituated to humans on a hill surrounded by cultivated fields (Cooper and Bernstein 2008). 


\subsubsection{Eastern Assamese Macaque (M. a. assamensis)}

Site 5 Wat Tham Pla $\left(20^{\circ} 19^{\prime} \mathrm{N}, 9^{\circ} 51^{\prime} \mathrm{E}, 843 \mathrm{~m}\right)$. I stayed at Wat Tham Pla (Tham Pla Temple), Pong Ngam, Mae Sai, Chiang Rai Province, Thailand, for a total of 110 days between 2008 and 2012. At this temple, Assamese macaques were provisioned and habituated to tourists and local people for more than 20 years. The monkeys slept on steep hills behind the temple at night, and they often stayed in the temple area in the daytime, because the monkeys were given foods such as bananas and peanuts every day. In this area, there were 193 monkeys with 26 adult males, 54 adult females, 24 male infants, and 16 female infants in 4 social groups (the A, B, C, and D groups) in January 2012. I identified all adult males and females in the social groups, based on their physical characteristics (Ogawa et al. 2009).

Site 6 Wat Tham Pha Tha Pol $\left(16^{\circ} 31^{\prime} \mathrm{N}, 100^{\circ} 40^{\prime} \mathrm{E}, 54 \mathrm{~m}\right)$. I stayed at Wat Tham Pha Tha Pol (Tham Pha Tha Pol Temple), non-hunting area, Amphoe Noen Maprang, Phitsanulok Province, Thailand, from 9 to 11 January 2009 with Eishi Hirasaki. This non-hunting area is surrounded by steep hills, but Assamese macaques were provisioned by tourists and local people at the temple outside of the non-hunting area.

\subsubsection{Tibetan Macaque (M. thibetana)}

Site 7 Mt. Emei $\left(29^{\circ} 33^{\prime} \mathrm{N}, 103^{\circ} 20^{\prime} \mathrm{E}, 1260-2100 \mathrm{~m}\right)$. I visited Mt. Emei (Emeishan), Sichuan Province, China, from 28 May to 1 June 1990 with Ming Li. Tibetan macaques were provisioned and habituated to tourists in this area (Zhao and Deng 1988). We made a round trip along the walking routes and observed monkeys in six social groups.

Site 8 Huangshan $\left(30^{\circ} 29^{\prime} \mathrm{N}, 118^{\circ} 11^{\prime} \mathrm{E}, 700-800 \mathrm{~m}\right)$. I stayed at Huangshan (Mt. Huang), Anhui Province, China, for a total of 382 days between 1989 and 1993. Wild Tibetan macaques in several social groups inhabited this area, as well as wild rhesus macaques (Wada et al. 1987). Since 1986, one social group, the Yulingkeng Group, has been provisioned for observations. Unlike now, no tourists visited there. The Yulingkeng Group had 42 monkeys with 7 adult males, 9 adult females, 3 male infants, and 3 female infants in November 1992. I identified all monkeys, based on their physical characteristics, and observed them sometimes with Kazuo Wada, Chenpei Xiong, Jinhua Li, Ming Li, and Qishan Wang (Ogawa 2006).

\subsubsection{Sampling Methods}

I used all occurrence behavior sampling in all of the study sites. In addition, I used focal animal sampling on adult males and adult females for $10 \mathrm{~h}$ each in both the 
mating and birth seasons, at Nagarjun in Nepal, Wat Tham Pla in Thailand, and Huangshan in China. For the focal sampling, I observed Assamese macaques at Nagarjun in Shivapuri-Nagarjun National Park from 30 July to 11 September 2014 in the birth season. S. Koirala and I observed them from 13 November 2014 to 15 January 2015 in the mating season and combined the data. I observed Assamese macaques at Wat Tham Pla in Thailand from 25 July to 7 September 2008 in the birth season and from 23 December 2010 to 8 January 2011 and from 31 December 2011 to 13 January 2012 in the mating season. I observed Tibetan macaques at Huangshan from 16 February to 26 April 1992 in the birth season and from 16 September to 4 November 1992 in the mating season.

The numbers of focal animals were 7 males and 7 females in the birth season and 7 males and 7 females in the mating season at Nagarjun; 10 males ( 5 in the A Group, 2 in the C Group, and 3 in the D Group) and 5 females ( 2 in the A Group, 1 in the C Group, and 2 in the D Group) in the birth season and 10 males (4 in the A Group, 2 in the C Group, and 4 in the D Group) and 5 females (3 in the A Group, 1 in the C Group, and 1 in the D Group) in the mating season at Wat Tham Pla; and 5 males and 9 females in the birth season and 6 males and 9 females in the mating season at Huangshan.

I calculated the frequency of behaviors, based on focal animal sampling. I combined the data by all occurrence behavior sampling and focal animal sampling to examine the presence/absence of behaviors and the rate of behaviors in which male and female infants were used in each study site.

\subsubsection{Definition of Behavior}

Bridging behavior is defined as "two individuals simultaneously lift up an infant" (Ogawa 1995, 2006, p. 52). If the two individuals are male, it is also called a triadic male-infant interaction. The typical interaction has the following sequence: (1) One adult holds a male or female infant ventrally. (2) The adult monkey carries the infant to another individual and presents it to the recipient. Another individual sometimes approaches the monkey who is holding the infant. (3) The two adults sat facing each other, one adult pulls up the infant's shoulder, the other pulls up its hip, the infant lays on its back, and the two adults lift up the infant together. As a result, the infant forms a bridge between them. While lifting up the infant, one or both adults often suck and/or touch the infant's genitalia with the expression of teeth chattering. Infants are handled gently and rarely show resistance or give signs of distress. After bridging, the two adults frequently stay in close proximity and groom each other, so this behavior may reduce social tension between the individuals and promote and maintain an affiliative relationship between males or between males and females. 
Table 10.1 Presence/absence of social behavior in each site

\begin{tabular}{|c|c|c|c|c|c|c|c|c|}
\hline \multirow{3}{*}{$\begin{array}{l}\text { Species } \\
\text { Country }\end{array}$} & \multicolumn{6}{|c|}{ Assamese macaque } & \multicolumn{2}{|c|}{ Tibetan macaque } \\
\hline & \multicolumn{3}{|c|}{ Western Assamese macaque } & ? & \multirow{2}{*}{\multicolumn{2}{|c|}{$\begin{array}{l}\text { Eastern } \\
\text { Assamese } \\
\text { macaque } \\
\text { Thailand }\end{array}$}} & & \\
\hline & \multicolumn{2}{|l|}{ Nepal } & \multicolumn{2}{|l|}{ India } & & & \multicolumn{2}{|c|}{ China } \\
\hline Site & Ramdi & Nagarjun & Siliguri & Tukreswari & $\begin{array}{l}\text { Tham } \\
\text { Pla }\end{array}$ & $\begin{array}{l}\text { Tham } \\
\text { Pha } \\
\text { Tha } \\
\text { Pol }\end{array}$ & Emei & Huangsham \\
\hline \multicolumn{9}{|l|}{$\begin{array}{l}\text { Presence } \\
\text { of } \\
\text { behavior }\end{array}$} \\
\hline $\begin{array}{l}\text { Bridging } \\
\text { between } \\
\text { males }\end{array}$ & No & No & $\mathrm{No}^{\#}$ & Yes & Yes & Yes & Yes & Yes \\
\hline $\begin{array}{l}\text { Sucking } \\
\text { of an } \\
\text { infant } \\
\text { genitalia } \\
\text { by males }\end{array}$ & No & No & $\mathrm{No}^{\#}$ & $\mathrm{No}^{\#}$ & Yes & Yes & Yes & Yes \\
\hline $\begin{array}{l}\text { Penis } \\
\text { sucking } \\
\text { between } \\
\text { adult } \\
\text { males }\end{array}$ & No & No & $\mathrm{No}^{\#}$ & $\mathrm{No}^{\#}$ & No & $\mathrm{No}^{\#}$ & Yes & Yes \\
\hline
\end{tabular}

Yes: the behavior was recorded. No: the behavior was not recorded. No ${ }^{\#}$ : Behavior was not recorded, possibly due to the short observational period at the study site. The study sites are arranged from west (left) to east (right). ?: It was not sure whether macaques here were Western Assamese macaques or Eastern Assamese macaques

\subsection{Results}

\subsubsection{Bridging Behavior}

Bridging behavior was recorded in Tibetan macaques at Huangshan and Mt. Emei in China and in Assamese macaques at Wat Tham Pha Tha Pol and Wat Tham Pla in Thailand and Tukreswari Temple in India (Table 10.1). However, no bridging behavior was recorded among any adults in Assamese macaques at Siliguri in India, Nagarjun in Nepal, and Ramdi Village in Nepal (Table 10.1). Although male Assamese macaques in these sites sometimes held an infant in front of another male, they never lifted the infant together with another male.

Figure 10.2 shows the frequency of bridging behavior at Nagarjun in Nepal, Wat Tham Pla in Thailand, and Huangshan in China, in which I observed 5-10 adult males and 5-9 adult females for $10 \mathrm{~h}$ each in the birth and mating seasons, respectively. Adult males of Tibetan macaque performed bridging behavior at the 

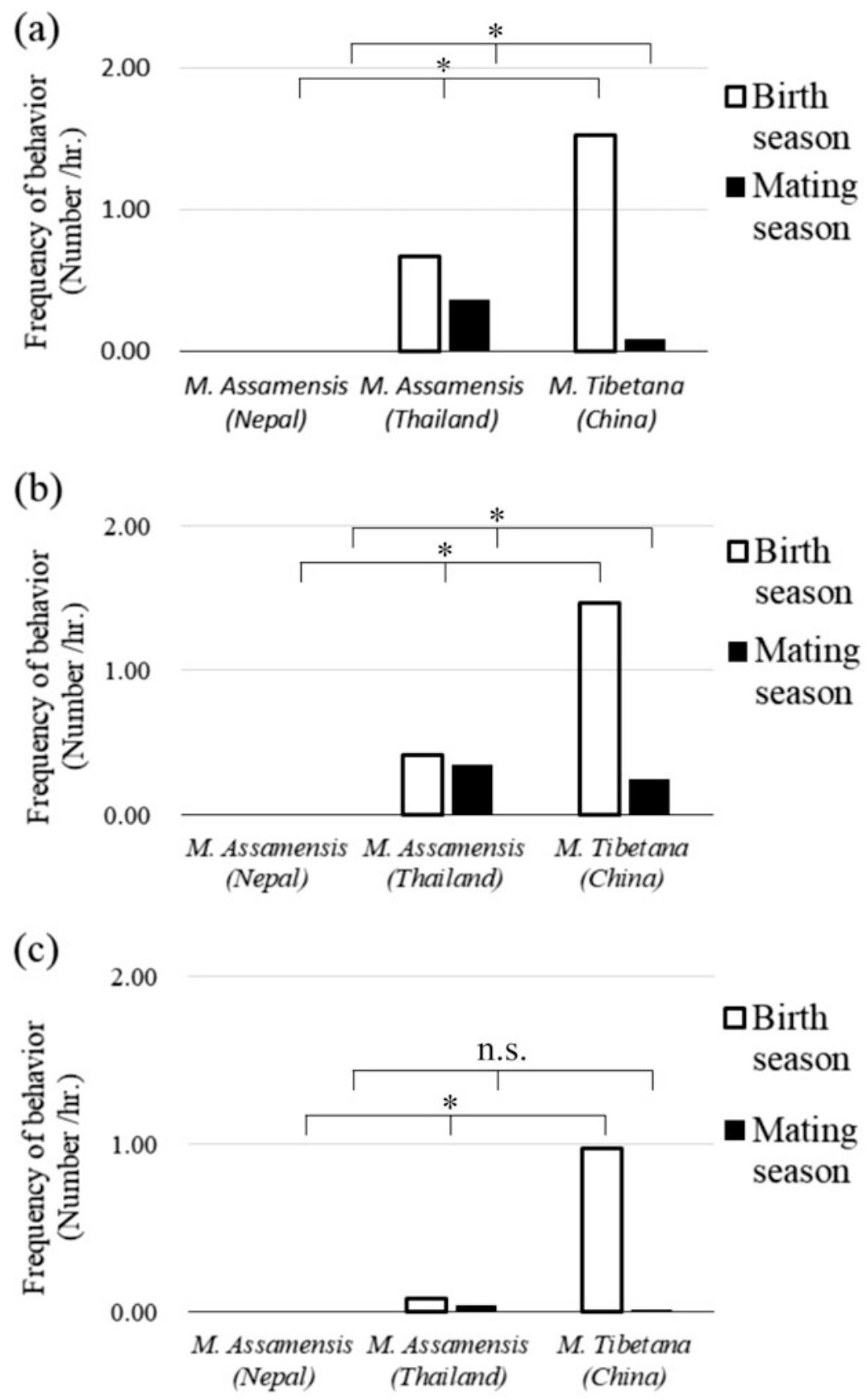

Fig. 10.2 Frequency of bridging behavior in the three study sites. Nepal: at Nagarjun, ShivapuriNagarjun National Park, Kathmandu District; Thailand: at Wat Tham Pla, Chiang Rai Province; China: at Huangshan, Anhui Province. ${ }^{*} p<0.05$. n.s. not significant. (a) Bridging between males, (b) bridging between females, (c) bridging between a male and a female 
frequency of 1.52 (average number of behaviors of each individual per hour) in the birth season and 0.08 in the mating season. Adult males of eastern Assamese macaque in Thailand performed bridging behavior at the frequency of 0.67 in the birth season and 0.36 in the mating season, whereas adult males of western Assamese macaques in Nepal did not perform bridging behavior at all. The frequencies of bridging behavior between adult males were significantly higher in Tibetan and eastern Assamese macaques than that in western Assamese macaques who did not perform bridging behavior (Kruskal-Wallis test, $n_{1}=5, n_{2}=10, n_{3}=7$, $H=12.964, p<0.05$ in the birth season; $n_{1}=6, n_{2}=5, n_{3}=7, H=13.112$, $p<0.05$ in the mating season). Tibetan and eastern Assamese macaques used a male infant in bridging more frequently than expected, if the number of male and female infants in the study group were considered (chi-squared test, $d f=1, \chi^{2}=70.2$, $p<0.05$ for Tibetan macaques; $d f=1, \chi^{2}=19.5, p<0.05$ for eastern Assamese macaques).

Adult females of Tibetan macaque performed bridging behavior at the frequency of 1.47 in the birth season and 0.41 in the mating season. Adult females of eastern Assamese macaque performed bridging behavior at the frequency of 0.24 in the birth season and 0.34 in the mating season, whereas adult females of western Assamese macaque did not perform bridging behavior at all. The frequencies of bridging behavior between adult females were also significantly higher in Tibetan and eastern Assamese macaques than that in western Assamese macaques who did not perform bridging behavior (Kruskal-Wallis test, $n_{1}=9, n_{2}=10, n_{3}=7, H=12.341$, $p<0.05$ in the birth season; $n_{1}=9, n_{2}=5, n_{3}=7, H=10.189, p<0.05$ in the mating season).

Bridging behavior between adult males and adult females occurred in Tibetan macaques at the frequency of 0.98 in the birth season and 0.01 in the mating season and in eastern Assamese macaques at the frequency of 0.09 in the birth season and 0.04 in the mating season, whereas western Assamese macaques did not perform bridging behavior between males and females. The frequencies of bridging behavior were significantly higher in Tibetan and eastern Assamese macaques in the birth season than that in western Assamese macaques who did not perform bridging behavior, though it was not significant in the mating season (Kruskal-Wallis test, $n_{1}=14, n_{2}=20, n_{3}=14, H=12.741, p<0.05$ in the birth season; $n_{1}=15$, $n_{2}=10, n_{3}=14, H=2.785$, n.s. in the mating season).

\subsubsection{Dyadic Male-Infant Interactions}

Adult males of Tibetan and Assamese macaques groomed and held an infant in their social group. Figure 10.3 shows the frequency of social grooming and holding an infant by adult males at Huangshan in China, Wat Tham Pla in Thailand, and Nagarjun in Nepal. There was no significant difference in the frequency of social grooming among the three sites (Kruskal-Wallis test, $n_{1}=5, n_{2}=10, n_{3}=7$, $H=0.863$, n.s. in the birth season; $n_{1}=6, n_{2}=5, n_{3}=7, H=1.380$, n.s. in the 
(a)
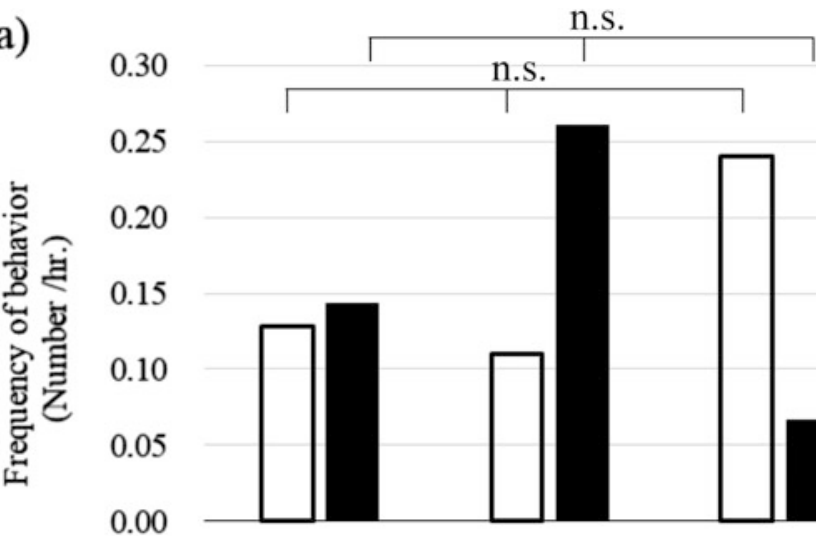

口Birth

season

20
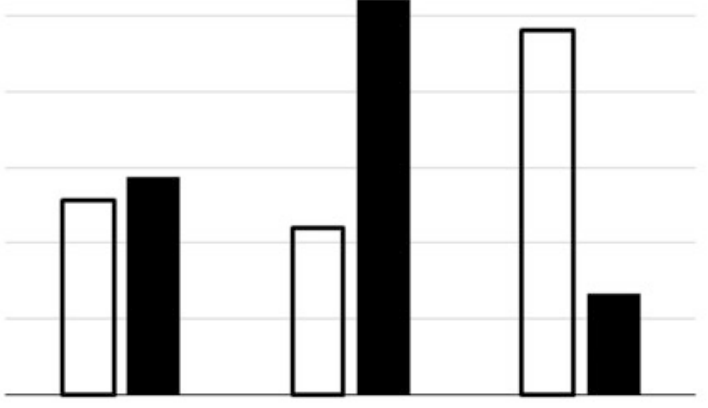

Mating

season

\section{Assamensis M Assamensis M Tibetama (Nepal) \\ (Thailand) \\ (China)}

(b)

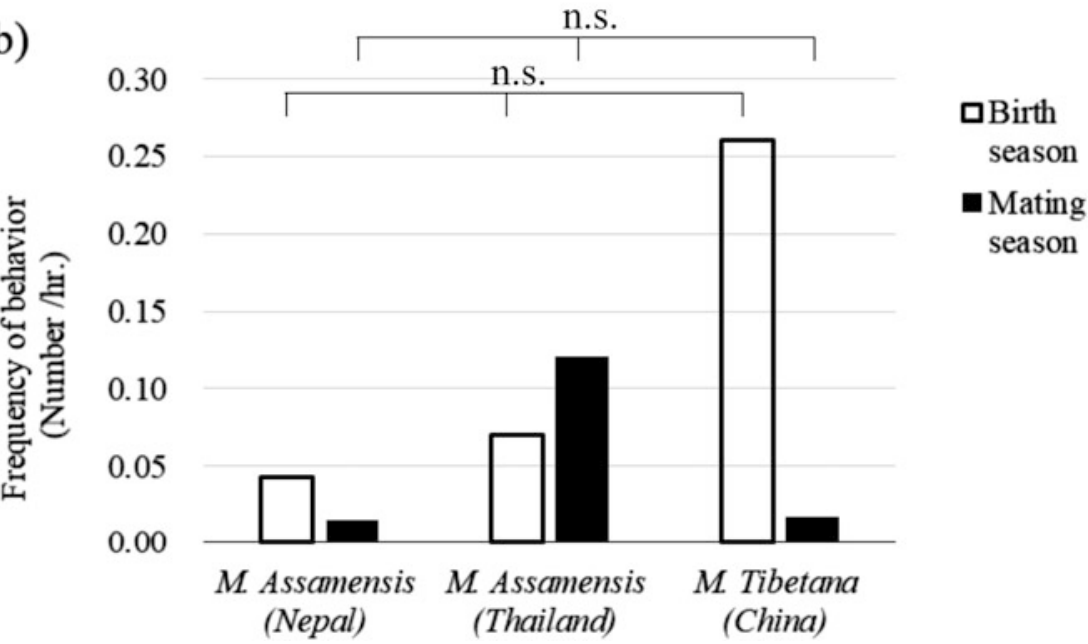

Fig. 10.3 Frequency of male-infant interactions in the three study sites. Nepal: at Nagarjun, Shivapuri-Nagarjun National Park, Kathmandu District; Thailand: at Wat Tham Pla, Chiang Rai Province; China: at Huangshan, Anhui Province. n.s. not significant. (a) Grooming an infant by adult males, (b) holding an infant by adult males

mating season). There was no significant difference in the frequency of holding among the three sites (Kruskal-Wallis test, $n_{1}=5, n_{2}=10, n_{3}=7, H=1.022$, n.s. in the birth season; $n_{1}=6, n_{2}=5, n_{3}=7, H=1.504$, n.s. in the mating season).

Adult males of Tibetan and Assamese macaques touched the genitalia of an infant, though this behavior was not confirmed at the sites in which the observational periods were short. 
In addition to genital manipulation, Tibetan macaques in China and Assamese macaques at Wat Tham Pha Tha Pol and Wat Tham Pla in Thailand and Tukreswari Temple in India sucked an infant's genitalia during bridging behavior and during dyadic interactions between adult males and infants (Table 10.1). However, Assamese macaques at Siliguri in India, Nagarjun in Nepal, and Ramdi in Nepal did not suck the infant's genitalia (Table 10.1). During penis sucking behavior by an adult male on an infant, the adult male usually lifted up the infant and sucked his penis, sometimes turning the infant upside down to do so. Male infants sometimes jumped onto an adult male's face, in order to have his penis sucked.

\subsubsection{Penis Sucking Between Adult Males}

Only Tibetan macaques performed penis sucking behavior between adult males (Table 10.1). Assamese macaques in any study sites never performed penis sucking behavior between adult males (Table 10.1).

\subsection{Discussion}

The current comparative study on social behavior revealed that Tibetan macaques and eastern Assamese macaques in Thailand performed bridging behavior between males, between females, and between males and females. Males of these macaques also sucked the genitalia of an infant during bridging behavior and dyadic interactions with an infant. On the contrary, western Assamese macaques in Nepal did not perform either bridging or genital sucking behavior. Assamese macaques at Tukreswari Temple also performed bridging behavior. The macaque species there can be regarded as eastern Assamese macaques, because this site is east (on the south bank) of the Brahmaputra River. Although they have been introduced as western Assamese macaque (Biswas et al. 2011; Cooper and Bernstein 2008), their phylogenetic status remains in question. Therefore, the facts that Tibetan and eastern Assamese macaques have bridging and genital sucking behaviors are generally consistent with the genetic and morphological evidence that Tibetan and eastern Assamese macaques shared a close phylogenetic relationship (Biswas et al. 2011; Chakraborty 2007; Sukmak et al. 2014). The fact that western Assamese macaques in Nepal did not show bridging behavior indicates that they are different from Assamese macaques in other populations. Though Assamese macaques in Nepal have been regarded as the same species with Assamese macaques in other populations, the classification in the sinica species-group is still controversial (Khanal et al. 2018). Further studies are needed to understand phylogenetic relationships among the species in the sinica species-group including Arunachal and whitecheeked macaques, which were recently recorded as new species ( $\mathrm{Li}$ et al. 2015; Sinha et al. 2005; but see Biswas et al. 2011). 


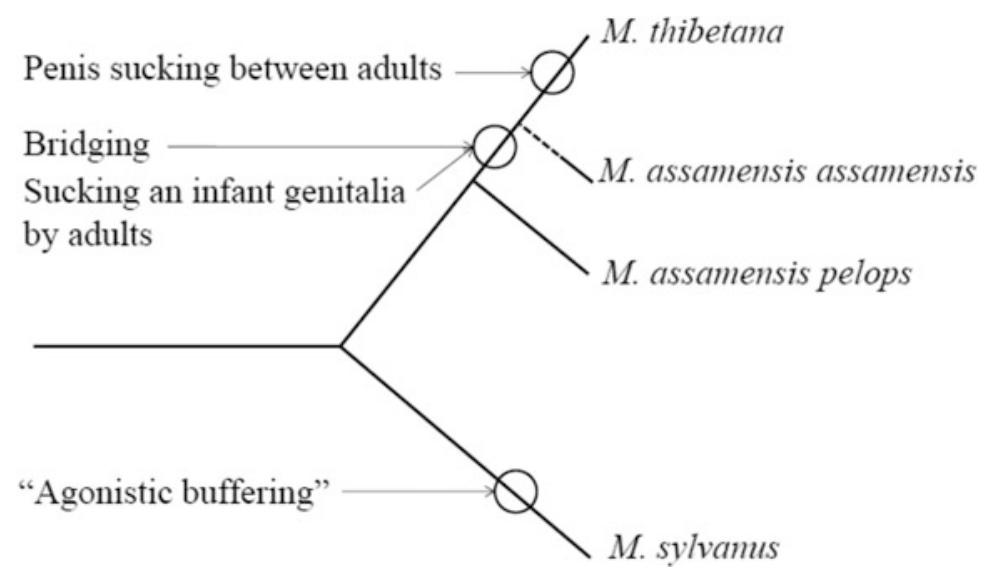

Fig. 10.4 Evolutionary scheme of bridging and penis sucking behaviors based on this comparative study, which shows that bridging and genital sucking behaviors evolved in the clade of Macaca thibetana and M. assamensis assamensis. In this figure, "agonistic buffering" in M. sylvanus evolved due to convergent evolution

Thus, the information on genetic and behavioral data is not complete. However, here I propose the hypothesis on the evolution of bridging and penis sucking behavior in macaques, based on the results of this study. Although it is not clear whether these social behaviors are genetically programmed or socially learned by cultural transmission, the difference of social behaviors by both of the two mechanisms is affected by the divergent evolutionary processes occurring in species, subspecies, and populations. I hypothesize that bridging and genital sucking behaviors evolved in the clade of Tibetan and eastern Assamese macaques in the sinica species-group, assuming that the Tibetan macaque was split from the eastern Assamese macaque (Fig. 10.4). As well as bridging behavior, many interactions between males and infants in eastern Assamese macaques in Thailand were similar to those in Tibetan macaques, though there might be some differences in frequencies, social contexts, functions, and the body form in the behavior (Ogawa, personal observation). In addition, eastern Assamese macaques in Thailand had various affiliative behaviors with body contact and sexual behaviors, most of which were similar to those of Tibetan macaques: social mount, hugging (embracing), genital showing, genital inspection, mating, and sexual harassment (Ogawa, personal observation).

It is also possible that the western Assamese macaques in Nepal lost the bridging behavior at some point in its evolutionary history. For example, similar to Tibetan and eastern Assamese macaques, stump-tailed macaques also frequently handled a newborn baby and performed bridging behavior between females one of which was the infant's mother (Estrada 1984; Maruhashi et al. 2018). Bridging behavior might occur between a mother and another female in the common ancestor of the sinica species-group including stump-tailed macaque, with some species engaging in frequent bridging between males and some species losing the bridging behavior. 
However, it is more parsimonious to argue that bridging behavior evolved in the clade of Tibetan and eastern Assamese macaque, rather than it was lost in western Assamese macaques, because there is no report that toque and bonnet macaques have bridging behavior, except for one study reporting triadic male-infant interactions in bonnet macaques (Silk and Samuels 1984). I predict that Arunachal and white-cheeked macaques will not have bridging behavior, either, if they are phylogenetically closer to western Assamese macaques.

If bridging behavior evolved in the sinica species-group, especially in the clade of Tibetan and eastern Assamese macaques, this explains why similar behavior has not been reported in other species-groups of macaques, though there is one report of triadic male-infant interactions in long-tailed macaque (M. fascicularis) (de Waal et al. 1976). The only exception is that Barbary macaques (M. sylvabus) have a behavior called "agonistic buffering" (Deag and Crook 1971). The behavioral sequence, social context, and functions of "agonistic buffering" have some similarities with bridging behavior in Tibetan and eastern Assamese macaques (Deag and Crook 1971; Paul 1999; Taub 1980). Indeed, two males of Barbary macaques handle an infant together and manipulate and/or suck the genitalia of the infant; however, they seem not to lift up the infant together in the same way that Tibetan and eastern Assamese macaques do. The "agonistic buffering" in Barbary macaques and bridging behavior in the sinica species-group might be evolutionarily different, if the origin of these behaviors was not very old in the sylvanus and sinica species-groups.

Besides, several species in the genus Papio also show triadic male-infant interactions (Packer 1980; Strum 1984). However, these interactions of baboons are quite different from bridging and "agonistic buffering" in macaques, because, unlike macaques, one of the two male baboons handles an infant in agonistic interactions. Bridging behavior in the sinica species-group, "agonistic buffering" in Barbary macaques, and triadic male-infant interactions in baboons might occur due to convergent evolution.

Among macaques, only male Tibetan macaques directly sucked the penis of another adult male, though bridging behavior was frequently accompanied with sucking the genitalia of an infant across the taxa I studied. Penis sucking behavior between adult males evolved only in the clade to which Tibetan macaques belong. Generally, monkeys form a social relationship with another individual by dyadic interactions, and they sometimes use a third individual to regulate the social relationship. Ogawa (2006, p. 66) discussed that "during bridging behavior, a monkey may be using the penis of an infant as a substitute for his own penis because the use of the infant's penis is more effective." However, male Tibetan and eastern Assamese macaques performed bridging behavior and genital sucking of an infant. Tibetan macaques might expand penis sucking behavior between males and infants toward penis sucking behavior between adult males. The socionomic sex ratios (number of adult males/number of adult females) in the study groups were 0.78 in Tibetan macaques, 0.54 in western Assamese macaques, and 0.48 in eastern Assamese macaques during the study periods. The high socionomic sex ratio in Tibetan macaques might promote penis sucking and other affiliative behaviors between adult males in this species (Ogawa 1995). 
In order to examine these hypotheses and predictions and to understand the evolution of the sinica species-group and the genus Macaca, further behavioral, genetic, and morphological studies are needed in Tibetan macaques, western and eastern Assamese macaques, and other macaque species in various areas.

\subsection{Summary}

1. Tibetan macaques and eastern Assamese macaques in Thailand performed bridging behavior, but western Assamese macaques in Nepal did not, though male western Assamese macaques in Nepal held an infant in front of another male.

2. Tibetan macaques and eastern Assamese macaques in Thailand sucked the genitalia of an infant, but western Assamese macaques in Nepal did not.

3. Only in Tibetan macaques did adult males perform penis sucking behavior with another adult male.

Acknowledgments I am grateful to the following people and organizations: in China, Dr. K. Wada at Kyoto University; Prof. Q. Wang, Mr. C. Xiong, Dr. J. Li, and Dr. M. Li at Anhui University; Mr. S. Zheng at Huangshan; Takashima Fund of Primate Society of Japan; JICA (Japan International Cooperation Agency); and JSPS KAKENHI Grant Numbers J1740480, 13740498; in Thailand, Dr. S. Malaivijitnond and Prof. S. Hannongbua at Chulalongkorn University; Dr. Y. Hamada at Kyoto University; Mr. L. Por, Mr. S. Win, Mr. S. Tirapanyo, and Mr. I. Ito, chief monks of Wat Tham Pla; National Research Council of Thailand (NRCT); and JSPS KAKENHI Grant Number 20255006; in Nepal, Dr. M. Chalise, Ms. S. Koirala, and Mr. B. Pandey at Tribhuvan University; Dr. Y. Kawamoto at Kyoto University; park rangers and staff of Shivapuri-Nagarjun National Park; Nepal Biodiversity Research Society; and JSPS KAKENHI Grant Numbers JP25440253 and JP16K07539; and in India, Mr. M. Bawri at Gauhati University; Dr. A. Sinha and Mr. N. Sharma at National Institute of Advanced Studies, Bangalore; Dr. M. Cooper at the University of Tennessee; Mr. G. S. S. Sarma at Tukreswari; and HOPE Project.

\section{References}

Balasubramaniam KN, Dittmar K, Berman CM, Butovskaya M, Cooper MA, Majolo B, Ogawa H, Schino G, Thierry B, de Waal FBM (2012) Hierarchical steepness and phylogenetic models: phylogenetic signals in Macaca. Anim Behav 83:1207-1218

Berman CM, Thierry B (2010) Variation in kin bias: species differences and time constraints in macaques. Behaviour 147:1863-1887

Biswas J, Borah DK, Das A, Das J, Bhattacharjee PC, Mohnot SM, Horwich RH (2011) The enigmatic Arunachal macaque: its biogeography, biology and taxonomy in northeastern India. Am J Primatol 73:1-16

Chakraborty D, Ramakrishnan U, Panor J, Mishra C, Sinha A (2007) Phylogenetic relationships and morphometric affinities of the Arunachal macaque, Macaca munzala, a newly described primate from Arunachal Pradesh, northeastern India. Mol Phylogenet Evol 44:838-849

Chalise MK, Ogawa H, Pandey B (2013) Assamese monkeys in Nagarjun forest of Shivapuri Nagarjun National Park, Nepal. Tribhuvan Univ J 18(1-2):181-190 
Cooper MA, Bernstein IS (2008) Evaluating dominance styles in Assamese and rhesus macaques. Int J Primatol 29:225-243

De Waal FBM, Luttrell LM (1989) Toward a comparative socioecology of the genus Macaca: different dominance styles in rhesus and stumptail monkeys. Am J Primatol 19:83-109

De Waal FBM, van Hooff JA, Netto WJ (1976) An ethological analysis of types of agonistic interaction in a captive group of Java-monkeys (Macaca fascicularis). Primates 17:257-290

Deag JM, Crook JH (1971) Social behaviour and "agonistic buffering" in the wild Barbary macaques, Macaca sylvana L. Folia Primatol 15:183-200

Delson E (1980) Fossil macaques, phyletic relationships and a scenario of deployment. In: Lindburg D (ed) The macaques: studies in ecology, behavior and evolution. Van Nostrand Reinhold, New York, pp 10-30

Estrada A (1984) Male-infant interactions among free-raging stumptail macaques. In: Taub DM (ed) Primate paternalism. Van Nostrand Reinhold, New York, pp 56-87

Fooden J (1982) Taxonomy and evolution of the sinica group of macaques: 3. Species and subspecies accounts of Macaca assamensis. Fieldiana. Zoology (New Series) 10:1-52

Groves CP (2001) Primate taxonomy: Smithsonian series in comparative evolutionary biology. Smithsonian Institution Press, Washington, DC

Kalbitz J, Schülke O, Ostner J (2017) Triadic male-infant-male interaction serves in bond maintenance in male Assamese macaques. PLoS One 12(10):e0183981

Khanal L, Chalise MK, Hei K, Acharya BK, Kawamoto Y, Jiang X (2018) Mitochondrial DNA analyses and ecological niche modeling reveal post-LGM expansion of the Assam macaque (Macaca assamensis) in the foothills of Nepal Himalaya. Am J Primatol 80(3):e22748

Koirala S, Chalise MK, Katuwal H, Gaire R, Pandey B, Ogawa H (2017) Diet and activity of Macaca assamensis in wild and semi-provisioned groups in Shivapuri Nagarjun National Park, Nepal. Folia Primatol 88:57-74

Li C, Chao Z, Fan P (2015) Whit-cheeked macaques (Macaca leucogenys): a new macaque species from Modog, Southeastern Tibet. Am J Primatol 77(2):753-766

Maruhashi T, Toyoda A, Malaivijitnond S (2018) Timing and characters of Touch Baby Genital (TBG) behaviours of Macaca arctoides inhabiting the Khao Krapuk Khao Taomo Non-hunting Area, Petchaburi, Thailand. Abstract. Satellite international symposium on Asian primates. Kathmandu, Nepal, pp 26-27

Ogawa $\mathrm{H}$ (1995) Bridging behavior and other affiliative interactions among male Tibetan macaques (Macaca thibetana). Int J Primatol 16:707-729

Ogawa H (2006) Wily monkeys: social intelligence of Tibetan macaques. Kyoto University Press and Trans Pacific Press, Kyoto

Ogawa H, Malaivijitnond S, Hamada Y (2009) Social interactions among Assamese macaques at Wat Tham Pla, Thailand. Proceedings. The 3rd international congress on the future of animal research, Bangkok, p 29

Packer C (1980) Male care and exploitation of infants in Papio anubis. Anim Behav 28:512-520

Paul A (1999) The sociobiology of infant handling in primates: is the current model convincing? Primates 40:33-46

Silk JB, Samuels A (1984) Triadic interactions among Macaca radiata: passports and buffers. Am J Primatol 6:373-376

Sinha A, Datta A, Madhusudan MD, Mishra C (2005) Macaca munzala: a new species from western Arunachal Pradesh, northeastern India. Int J Primatol 26(4):977-989

Strum SC (1984) Why males use infants. In: Taub DM (ed) Primate paternalism. Van Nostrand Reinhold, New York, pp 20-55

Sukmak M, Malaivijitnond S, Schülke O, Ostner J, Hamada Y, Wajjwalku W (2014) Preliminary study of the genetic diversity of eastern Assamese macaques (Macaca assamensis assamensis) in Thailand based on mitochondrial DNA and microsatellite markers. Primates 55:189-197

Taub DM (1980) Testing the "agonistic buffering" hypothesis. Behav Ecol Sociobiol 6:187-197

Thierry B, Singh M, Kaumanns W (eds) (2004) Macaque societies: a model for the study of social organization. Cambridge University Press, Cambridge 
Wada K (2005) The distribution pattern of rhesus and Assamese monkeys in Nepal. Primates 46:115-119

Wada K, Xiong C, Wang Q (1987) On the distribution of Tibetan and rhesus monkeys in southern Anhui, China. Acta Theriol Sinica 7:148-176

Zhao Q, Deng Z (1988) Macaca thibetana at Mt. Emei, China: I. A cross-sectional study of growth and development. Am J Primatol 16:251-260

Open Access This chapter is licensed under the terms of the Creative Commons Attribution 4.0 International License (http://creativecommons.org/licenses/by/4.0/), which permits use, sharing, adaptation, distribution and reproduction in any medium or format, as long as you give appropriate credit to the original author(s) and the source, provide a link to the Creative Commons licence and indicate if changes were made.

The images or other third party material in this chapter are included in the chapter's Creative Commons licence, unless indicated otherwise in a credit line to the material. If material is not included in the chapter's Creative Commons licence and your intended use is not permitted by statutory regulation or exceeds the permitted use, you will need to obtain permission directly from the copyright holder. 